\title{
De uma falta ontológica a uma política do tempo*'
}

\section{From an ontological lack to a politics of time}

\author{
Ruben Artur Lemke*2 \\ Tiago Ravanello*3 \\ Marcio Luis Costa*4
}

\begin{abstract}
Neste artigo os autores apresentam uma análise da dimensão temporal da concepção psicanalítica da falta-a-ser utilizando elementos da analítica existenciária presente em Ser e Tempo, de Heidegger. A partir disso, é discutida a função do corte, que revela o sujeito como descontinuidade no real, tal como foi proposto por Lacan no seminário $\mathrm{O}$ desejo e sua interpretação. Por fim, a categoria "corte" é proposta como o corolário técnico da proposição ontológica da falta-a-ser e o modo de operacionalizar a política da psicanálise em sua relação com a temporalidade do tratamento.
\end{abstract}

Palavras-chave: Psicanálise, analítica existenciária, corte, falta-a-ser

*1 O presente artigo é uma versão modificada de um trabalho de mesmo título, apresentado no dia 10 de de novembro de 2018, na cidade de São Paulo, no XIX Encontro Nacional da Escola de Psicanálise do Fórum do Campo Lacaniano: Estratégia, tática e política da psicanálise.

*2 Secretaria Municipal de Saúde de Campo Grande (Campo Grande, MS, Brasil).

*33 Universidade Federal de Mato Grosso do Sul - UFMS (Campo Grande, MS, Brasil).

*4 Universidade Católica Dom Bosco (Campo Grande, MS, Brasil). 
A falta-a-ser (manque-à-être) é proposta por Lacan (1958/1998e) como a política da psicanálise e como o nível em que o analista deve se situar para que possa se orientar em sua estratégia e em sua tática, ou seja, no manejo da transferência e nos usos da interpretação. A falta, na teoria psicanalítica, é efeito da subversão do sujeito pela linguagem e é imanente à estrutura do desejo. Nesse quadro ontológico, Lacan (1958-59/2016) afirma que é "a linguagem que introduz a dimensão do ser para o sujeito e, ao mesmo tempo, a tira dele" (p. 159). O desejo é conceituado por Lacan (1958/1998e) como a "metonímia da falta-a-ser" (p. 629) e sobre o movimento metonímico, se refere deste modo no seminário VII: "O arroio onde se situa o desejo não é apenas a modulação da cadeia significante, mas o que corre por baixo, que é, propriamente falando, o que somos, e também o que não somos, nosso ser e nosso não ser" (Lacan, 1959-60/2008a, p. 376).

Ao propor a falta-a-ser como a política que orienta a estratégia e a tática do analista, o autor estaria assentando a direção do tratamento em uma posição ontológica? Ou estaria apenas utilizando uma metáfora ontológica? Em que consistiria a expressão falta-a-ser? Quais seriam os diversos sentidos que se poderia depreender desta expressão? Seria um oxímoro? Estaria se referindo ao sujeito sem substância da psicanálise, que insiste nos intervalos da cadeia significante? Ou a um tempo de inacabamento que não se esgota em uma plenitude? Seria uma leitura ontológica da castração freudiana? O encaminhamento que pretendemos dar para este conjunto de perguntas é o de uma retomada de um diálogo com Ser e Tempo, de Heidegger. Na construção dos alicerces da teoria do desejo, Lacan manteve um debate com temas heideggerianos, onde a temporalidade é de 


\section{ARTIGOS}

suma importância. $\mathrm{O}$ autor relaciona a entrada no significante com a assunção do ser-para-a-morte (Sein zum Tode). Em um período anterior, no texto sobre o tempo lógico, a figura central é a assunção da certeza antecipada. A antecipação é um tema central do cuidado (Sorge) em Heidegger, que aparece em Ser e Tempo como o Sichvorweg (ser-adiantado-em relação-a-si). Assim, pretendemos abordar a falta-a-ser no sentido de sua dimensão temporal de um não acabamento lançado ao futuro. ${ }^{1} \mathrm{O}$ tempo é o fundamento lógico da existência e só adquire certa substancialidade quando é lançado no encontro de sua própria finitude. Retomar estas discussões tem como objetivo demonstrar a importância ontológica de pontos centrais na política da psicanálise, como o são o tempo lógico e o corte. O corte possui a dignidade do ser, afirma Lacan (1958-59/2016). Não compreender a origem ontológica desses conceitos é lançá-los no risco de decaírem em um uso banal de mera regra técnica ou de figura identitária de estilo.

\section{Dimensão temporal da falta-a-ser}

A falta é um efeito da subversão do sujeito pela linguagem. Na teoria psicanalítica a linguagem fere de morte a consistência do ser (López, 2011) e o desejo comporta a noção de que há uma dimensão irrecuperável do ser para o sujeito. A falta-a-ser, de acordo com Juranville (1987) é a consequência ontológica da entrada do significante no mundo humano. A incidência da falta sobre o ser do sujeito se dá na teoria do desejo em diversos sentidos. Primeiro, o sujeito não é localizável na cadeia significante. Ele está no intervalo e não tem consistência substancial. Não existe um significante que represente o sujeito na cadeia, assim como não há um significante que represente o ser do sujeito. Lacan (1958-59/2016) afirma que o sujeito, tal como Freud o propõe, é um sujeito que não pode ser pensado como o sujeito da filosofia, como suporte universal dos objetos, mas, "o negativo deste [...] estruturado numa relação complexa com o significante" (p. 317). O sujeito da psicanálise não pode ser pensado nos moldes da substância (Ov̉oía),

${ }^{1}$ A analítica existenciária utiliza expressões como noch-nicht-sein (ainda-não-sendo) e o ständige Ausstand (faltante constante) para analisar a relação do Dasein com o tempo (Heidegger, 2012). 
como o substrato que funcionaria como suporte ao fluxo das modificações acidentais do significante. O sujeito está, em sua relação com o significante, em posição de eclipse (Lacan, 1958-59/2016), e tem-se notícias dele por suas irrupções. Esta concepção de sujeito se coaduna com o modo temporal das manifestações pulsáteis do inconsciente abordadas por Lacan (1964/2008b) no seminário XI.

De acordo com López (2011), a falta-a-ser opera como um campo de determinação e compõe o núcleo do inconsciente, de onde o ser advém como falta-a-ser. Como diz Lacan (1960/1998f), o sujeito do inconsciente advém como "ser de não ente" (p. 816). No seminário XI o autor afirma que é "o sujeito humano, vivo, que introduz uma nadificação no real" (Lacan, 195859/2016, p. 373). Esta expressão guarda ressonâncias com a afirmação de Heidegger (1929/1999) de que o homem realiza a experiência do ser através do nada. Lacan (1964/2008b) lembra que foi Heidegger quem demonstrou o poder de nadificação na experiência do ser. Heidegger (1927/2012) afirma que faltar possui o significado de não subsistência, que é uma característica fundamental do ser em sua diferença com o ente. Deste modo, no quadro da diferença ontológica, existe certo avizinhamento entre ser e falta.

$\mathrm{Na}$ analítica existenciária presente em Ser e Tempo, a existência apresenta como um traço originário de sua finitude a marca fundamental de sua ausência de plenitude (Alemán \& Larriera, 2009). A existência padece de um defeito (Mangel) ontológico originário em sua condição de ser ejetado no mundo. Desse modo, o homem carrega não ser em seu surgimento, pois em sua situação fática está ancorado em circunstâncias que não pôde escolher e que só pode ultrapassar de modo limitado. Em sua condição de estar ejetado sem fundamento algum, o Dasein ${ }^{2}$ é um campo de possibilidades, mas estas possibilidades são finitas, de modo que o homem está sempre aquém delas, permanecendo em um estado de inautenticidade e refugiado de seu desamparo

${ }^{2}$ Dasein é uma expressão que une a palavra alemã Sein com a partícula $D a$. Nas traduções para as línguas neolatinas é proposto como "ser-aí", "être-là" e "esser-ci". Fausto Castilho, em sua tradução optou por deixar como no original do texto de Heidegger (1927/2012), com exceção de quando há um hífen entre as palavras, situação em que o autor traduz como "ser-aí". Ernildo Stein $(1999,2011)$ traduz como "ser-aí". Outros autores como Gianni Vattimo traduzem como “estar-aí”. Alemán e Larriera (2009) optaram por utilizar o termo ex-sistencia para designar o Dasein, seguindo Manuel Jiménez Redondo. No presente artigo, por procedermos a leitura da tradução de Fausto Castilhos, mantivemos Dasein no original. 


\section{ARTIGOS}

nas banalidades cotidianas. $\mathrm{O}$ ser, por não estar nunca em posse de sua plenitude, não passa de um projeto, sempre inacabado, que se dá na forma de uma insistência (Heidegger, 1927/2012). Esta insistência possui um modo próprio de temporalidade.

A única substância do homem é sua existência, que só pode ser compreendida no horizonte do tempo. O tempo próprio de cada sujeito se organiza no adiantar-se, sendo o ponto final o que pode dar alguma consistência ao tempo, arrancando-o da suspensão de uma temporalidade imprópria que mantém o homem em uma existência inautêntica. O tempo impróprio é o sentido comum de tempo, entendido como uma sucessão de "agoras" passível de medida e sem limites lógicos. A morte, como o que há de mais próprio, remete cada um a si mesmo, produzindo uma temporalidade própria. A angústia posiciona o homem diante do nada que desvela a nulidade que determina o Dasein em seu fundamento, que é ser dejetado irreversivelmente em direção à morte: a possibilidade mais própria, certa, intransferível e indeterminada. A morte não significa um final que se espera, mas o fato de que existimos de modo finito (Heidegger, 1927/2012).

O modo de assumir como próprio o conjunto articulado das estruturas existenciais é o antecipar-se em relação a si. Esta figura do tempo está presente em Lacan (1949/1998a) no estádio do espelho, como a assunção antecipada da imagem unificada do corpo, ou no sofisma dos três prisioneiros, na forma da asserção da certeza antecipada (Lacan, 1945/1998b). Antecipação e certeza são temas da analítica existenciária, pois a antecipação é o modo de ser da preocupação (cuidado) e a certeza é o estado subjetivo da verdade. O sofisma dos três prisioneiros é um trabalho lógico que tem como pano de fundo uma concepção ontológica do tempo: assim, o instante de ver pode ser pensado como o instante do abrir os olhos para o aí da situação fática, o tempo de compreender como o do advento da verdade e o momento de concluir, como o assumir decidido e ser-resoluto no adiantar-se à situação em relação à qual sempre já se está em atraso.

Como demonstra o esquema do pente invertido de Freud (1900-1901/1996) em A interpretação dos Sonhos, o tempo do desejo é o tempo do avançar em direção a um traço anterior perdido. A falta-a-ser carrega uma ideia de futuro, de um tempo de incompletude, de algo que é convocado a partir do porvir para a realização, ao mesmo tempo em que mantém um tensionamento com a estaticidade da palavra falta. Na analítica existenciária de Heidegger (1927/2012) o presente se temporaliza como o advir de um futuro finito, que se retrai sobre o ser-sido, como um recolhimento das 
diferentes modalidades de temporalização do tornar presente. É a linguagem que permite a experiência do tempo, graças às propriedades de recolhimento do logos, que coloca esperanças, lembranças e entes do mundo circundante em uma mesma estrutura no modo de um presentar (Heidegger, 1956). Ser é temporalizar a si mesmo.

O tempo próprio é uma produção singular e horizonte no qual o ser se dá: "Es gibt. ${ }^{3} \mathrm{O}$ tempo possui uma dimensão ética, pois se refere ao fato de que somos lançados em uma corrida em direção à morte e essa condição convoca a questão do que fazer com o escasso tempo que nos cabe. É sobre esse fundo ontológico que se inscreve a ética do desejo. Por último, Lacan escolheu a palavra cura para se referir a uma análise e há nisto a intensão de ressaltar o caráter temporal da direção de um tratamento ${ }^{4}$ (Aleman \& Larriera, 2009).

A questão que se coloca é que na impossibilidade de pensar o sujeito do inconsciente por meio das categorias ligadas à substância aristotélica, os fenômenos de irrupção do sujeito só podem ser pensados em sua dimensão temporal. É nesse sentido que Lacan apresenta uma teoria do sujeito como descontinuidade no real.

\section{O corte como corolário técnico da falta-a-ser}

No seminário VI, Lacan (1958-1959/2016) apresenta sua teoria do sujeito como efeito de uma cadeia articulada que tem o ser como suporte:

o sujeito se reconhece no fato de ser sujeito de uma cadeia articulada, que é da ordem de um discurso. Ora, um discurso não se sustenta sem um suporte, e não é abusivo qualificar este suporte em termos de ser. Afinal, se o termo ser quer dizer alguma coisa, se lhe dermos sua definição mínima, essa coisa é o real, na medida em que se inscreve no simbólico. (p. 408)

Nesse seminário, o autor considera o corte a última característica estrutural do simbólico e propõe que o sujeito que desliza sobre o suporte do

${ }^{3}$ A palavra alemã Es Gibt significa "existe", o que está dado na existência.

${ }^{4}$ Embora na edição dos Escritos traduzida para o português tenha sido escolhida a palavra tratamento, no texto original a palavra escolhida por Lacan foi cure: "La direction de la cure et les principes de son pouvoir". De acordo com Aleman e Larriera (2009) esta escolha foi influência do Sorge (cuidado, preocupação) de Heidegger em Ser e Tempo, que alguns tradutores espanhóis traduzem como cura. 


\section{ARTIGOS}

discurso pode ser apreendido nas rupturas. O simbólico articula um real que neste momento da teoria se inscreve no plano do ser. Por isso, Lacan (19581959/2016) afirma que o corte tem a dignidade do ser, dignidade que provém do ato do corte enquanto tal. Segundo o autor, esta região apontada pelo corte tem uma vizinhança com o que Freud chamou de pulsão de morte, naquilo que ela pode produzir convergência com o ser. $\mathrm{O}$ corte permite o advento do "ser puro de sujeito", afirma Lacan (p. 426), "[...] o real do sujeito, que é o advento do ser para além de toda realização subjetiva possível” (p. 429).

Lacan (1958-1959/2016) ainda afirma: "Pois existe esse corte essencial de sua existência, a saber, que ele é aí e tem de se situar no fato mesmo do advento do corte" (p. 429). Essa afirmação traz ressonâncias da analítica existenciária, pois o Dasein, o ser-aí, é o lugar da pergunta pelo sentido do ser, no confronto com a própria finitude..$^{5}$ Lacan prossegue: "O ser não está em nenhum outro lugar [...] senão nos intervalos, ali onde ele é o menos significante dos significantes, ou seja, no corte. O ser é a mesma coisa que o corte. O corte o presentifica no simbólico" (p. 437) e pode revelar a estrutura do sujeito como uma descontinuidade no real. Ou seja, o corte revela o sujeito em sua falta-a-ser.

\section{Considerações finais}

Esta discussão ontológica sobre o corte como contendo a dignidade do ser, fornece as coordenadas para se pensar a função do corte na direção de um tratamento. $\mathrm{O}$ ato analítico do corte carrega a modalidade temporal da surpresa e introduz a função da pressa. Deste modo produz uma temporalidade própria que rompe com o tempo impróprio da aceleração cotidiana. De acordo com Triska e D'Agord (2013), o corte é o modelo lógico que fundamenta a interpretação, o ato analítico e gostaríamos de acrescentar aqui, o tempo lógico nas sessões analíticas. O corte interpretativo está baseado numa concepção ontológica não substancialista, de pensar o sujeito como uma descontinuidade no real e o tempo na direção de uma análise, não como um continuum linear do qual se participa, mas como uma produção singularizante do sujeito. O tempo do cuidado (Sorge) em Heidegger (1927/2012), que Lacan traduz como tempo da cura, é o tempo do adiantar-se, onde há uma

${ }^{5} \mathrm{Ou}$ seja, tendo o tempo como horizonte da pergunta pelo ser. 
participação ativa do Dasein. O tempo não é algo que ocorre ao Dasein, mas o que o Dasein é: essencialmente tempo. Nesse sentido, o corte nas sessões confronta o sujeito com a finitude do tempo e com a indeterminação do fim e por esse motivo tem a função técnica de convocar o sujeito a se apropriar de seu tempo e abandonar a suspensão da procrastinação neurótica.

Ao propor a equalização entre o ser e o real e formalizá-los como estruturalmente vinculados ao simbólico, sendo o corte o que permite o seu advento, o corte interpretativo é uma consequência da proposição ontológica da falta-a-ser, da qual deriva a política do tratamento. O corte é um modo de operacionalização da política nos seus modos de operar com a estratégia e a tática. $\mathrm{O}$ corte remete o sujeito à sua falta-a-ser, mas isso não significa apologia à resignação. A falta-a-ser trata dos limites lógicos sobre os quais uma existência pode realizar suas possibilidades. Pois, se pode realizar apenas algumas entre tantas, importa que sejam realizadas as mais próprias. Ao organizar o tempo a partir do futuro, o corte final da existência remete cada sujeito a assumir uma temporalidade própria e se projetar resolutamente em direção àquelas possibilidades que the são mais caras, aquelas das quais o sujeito não se perdoa de declinar. A psicanálise chama isso de assumir de modo decidido o próprio desejo.

A falta-a-ser propõe uma política radicalmente diferente da política da vontade de potência, que resultaria para um analista numa aposta nos poderes de um ego exercendo tecnicamente sua soberania sobre os entes do mundo. A política da psicanálise se insere em uma tradição de crítica à metafísica que visa as condições de possibilidade para a emergência de algo da ordem do ser. Como tal, a psicanálise exige um proceder diferente dos procedimentos operativos da técnica sobre o ente e sua substância, assim como de uma relação com o tempo diferente da cronologia dos relógios. A psicanálise exige uma política que incida sobre a temporalidade singular de cada sujeito e, nesse sentido, o corte é proposto como um modelo formal para a técnica analítica e é coerente com uma concepção não substancialista do sujeito como descontinuidade no real.

\section{Referências}

Alemán, J., \& Larriera, S. (2009). Desde Lacan: Heidegger - Textos reunidos. (Spanish Edition) (Edição do Kindle. ISBN: 978-84-88326-99-7). Malágara: Miguel Gomes Ediciones. 


\section{ARTIGOS}

Freud, S. (1996). A interpretação dos sonhos. In Edição Standard Brasileira das Obras Psicológicas Completas de Sigmund Freud (Vol. IV e V). Rio de Janeiro, RJ: Imago. (Trabalho original publicado em 1900-1901).

Heidegger, M. (1999). Que é metafísica? In Conferências e escritos filosóficos. Martin Heidegger. (Trad. e notas Ernildo Stein). São Paulo, SP: Nova Cultural. (Trabalho original publicado em 1929).

Heidegger, M. (2012). Ser e tempo (Trad., org., nota prévia, anexos e notas: Fausto Castilho). Campinas, SP: Editora da Unicamp/Petrópolis, RJ: Vozes. (Trabalho original publicado em 1927).

Heidegger, M. (1956). Logos (Trad. Jaques Lacan. Traduction d'un texte de Martin Heidegger - Logos, paru dans La psychanalyse, 1, 59-79. Recuperado em 29 jan. 2018 de: <http://parolesdesjours.free.fr/heideggerlacan.pdf. Versão em espanhol: http://www.ub.edu/las_nubes/archivo/uno/wunderkammer/Texto/Filosofia/Logos. pdf $>$.

Juranville, A. (1987). Lacan e a filosofia (Trad. Vera Ribeiro. Revisão Técnica: Luiz Alfredo Garcia-Rosa). Rio de Janeiro, RJ: Jorge Zahar.

Lacan, J. (1998a). O estágio do espelho como formador da função do eu tal como nos é revelado na experiência psicanalítica. In Escritos. Rio de Janeiro, RJ: Jorge Zahar (Trabalho original publicado em 1949).

Lacan, J. (1998b). O tempo lógico e a asserção da certeza antecipada. In Escritos. Rio de Janeiro, RJ: Jorge Zahar. (Trabalho original publicado em 1945).

Lacan, J. (1998c). Função e campo da fala e da linguagem em psicanálise. In Escritos. Rio de Janeiro, RJ: Jorge Zahar. (Trabalho original publicado em 1956).

Lacan, J. (1998d). A instância da letra no inconsciente ou a razão desde Freud. In Escritos. Rio de Janeiro, RJ: Jorge Zahar. (Trabalho original publicado em 1957).

Lacan, J. (1998e). A direção do tratamento e os princípios de seu poder. In Escritos. Rio de Janeiro, RJ: Jorge Zahar. (Trabalho original publicado em 1958).

Lacan, J. (1998f). Subversão do sujeito e dialética do desejo no inconsciente freudiano. In Escritos. Rio de Janeiro, RJ: Jorge Zahar. (Trabalho original publicado em 1960).

Lacan, J. (2016). O seminário. Livro 6. O desejo e sua interpretação. (Texto estabelecido por Jacques Alain Miller. Trad. de Cláudia Berliner). Rio de Janeiro, RJ: Jorge Zahar. (Trabalho original publicado em 1958-59).

Lacan, J. (2008). O seminário. Livro 7. A ética da psicanálise. (Texto estabelecido por Jacques Alain Miller. Trad. de Antônio Quinet). Rio de Janeiro, RJ: Jorge Zahar (Trabalho original publicado em 1959-60).

Lacan, J. (2008). O seminário. Livro 11. Os quatro conceitos fundamentais da psicanálise. (Texto estabelecido por Jacques Alain Miller. Trad. de M.D. Magno). Rio de Janeiro, RJ: Jorge Zahar. (Trabalho original publicado em 1964). 
López, H. (2011). Lo fundamental de Heidegger en Lacan (2 $2^{\mathrm{a}}$ ed.). Buenos Aires, AR: Letra Viva.

Stein, E. (1999). Notas do tradutor. In Martin Heidegger, Conferências e escritos filosóficos. São Paulo, SP: Nova Cultural.

Stein, E. (2011). Introdução ao pensamento de Martin Heidegger. Porto Alegre, RS: EdiPUCRS.

Triska, V. H. C., \& D’Agord, M. R. de L. (2013). O corte interpretativo em psicanálise. Psicologia: Teoria e Pesquisa, 29(4), 361-367. https://dx.doi. org/10.1590/S0102-37722013000400002

\section{Resumos}

(From an ontological lack to a politics of time)

This article presents an analysis of the temporal dimension of a psychoanalytical concept called lack-of-being using elements of Heidegger's existential analysis he describes in Being and Time. Based on that, we discuss the function of the cut, which reveals the subject as discontinuity in the real, as proposed by Lacan in his seminar Desire and its interpretation. To conclude, the category of the cut is proposed as the technical corollary of the ontological proposition of lack-ofbeing and the way to operationalize the politics of psychoanalysis in its relation to the temporality of the treatment.

Key words: Lacanian psychoanalisis, Existential analytic, cut, lack-of-being

(D’un manque ontologique à une politique du temps)

Cet article présente une analyse de la dimension temporelle de la conception psychanalytique du manque à être en utilisant des éléments de l'analyse existentielle que Heidegger décrit dans "Être et temps ». Ensuite, on discute la fonction de l' " après-coup " qui permet de voir un sujet en tant que discontinuité dans le réel, comme l'a proposé Lacan dans son séminaire "Le désir et son interprétation ». Enfin, le concept d'après-coup est proposé comme corollaire technique de la proposition ontologique du manque à être et comme moyen de rendre opérationnelle la politique de la psychanalyse dans son rapport avec la temporalité du traitement.

Mots clés: Psychanalyse, analyse existentielle, coupe, manque à être

(De una falta ontológica a una política del tiempo)

En este artículo, los autores presentan un análisis de la dimensión temporal de la concepción psicoanalítica de la falta-en-ser, utilizando elementos del análisis existencial presente en Ser y Tiempo, de Heidegger. Desde este análisis, se discute 


\section{ARTIGOS}

la función del corte, categoría que revela al sujeto como discontinuidad en lo real, como lo propuso Lacan en el seminario El deseo y su interpretación. Para finalizar, los autores proponen el concepto de corte como el corolario técnico de la propuesta ontológica de la falta-en-ser y la forma de operacionalizar la política del psicoanálisis en su relación con la temporalidad de la cura.

Palabras clave: Psicoanálisis, análisis existencial, corte, falta-en-ser

Citação/Citation: Lemke, R. A., Ravanello, T., \& Costa, M. L. (2021, março). De uma falta ontológica a uma política do tempo. Revista Latinoamericana de Psicopatologia Fundamental, 24(1), 63-74. http://dx.doi.org/10.1590/1415-4714.2021v24n1p63.4.

Editora/Editor: Profa. Dra. Sonia Leite

Submetido/Submitted: 30.12.2019/ 12.30.2019 Revisado/Revised: 26.5.2020 / 5.26.2020

Aceito/Acepted: 7.9.2020 / 9.7.2020

Copyright: (C) 2009 Associação Universitária de Pesquisa em Psicopatologia Fundamental/ University Association for Research in Fundamental Psychopathology. Este é um artigo de livre acesso, que permite uso irrestrito, distribuição e reprodução em qualquer meio, desde que o autor e a fonte sejam citados / This is an open-access article, which permits unrestricted use, distribution, and reproduction in any medium, provided the original authors and sources are credited.

Financiamento/Funding: Este trabalho recebeu apoio da Coordenação de Aperfeiçoamento de Pessoal de Nível Superior - Capes (Brasília, DF, Br) / This work is supported Coordenação de Aperfeiçoamento de Pessoal de Nível Superior - Capes (Brasília, DF, Br).

Conflito de interesses/Conflict of interest: Os autores declaram que não há conflito de interesses. / The authors declare that there is no conflict of interest.

\section{Ruben ARTUR Lemke}

Doutor em Psicologia pelo Programa de Mestrado e Doutorado em Psicologia da Universidade Católica Dom Bosco - UCDB (Campo Grande, MS, Br); Mestre em Psicologia Social pela Universidade Federal do Rio Grande do Sul - UFRGS (Porto Alegre, RS, Br); Residência em Saúde Mental Coletiva pela Escola de Saúde Pública do Rio Grande do Sul (Porto Alegre, RS, Br); Graduação em Psicologia pela Universidade Luterana do Brasil (Canoas, RS, Br). Coordenador do Programa de Residência Multiprofissional em Saúde Mental da Secretaria Municipal de Saúde de Campo Grande (Campo Grande, MS, Br).

Rua Onória Martins Pereira 82. B1 F ap 14 - Bairro Monte Castelo

79011-535 Campo Grande, RS, Br

lemke.ruben@gmail.com

https://orcid.org/0000-0002-4892-9308 
Tiago Ravanello

Pós-Doutor em Psicologia Clínica pela Universidade de São Paulo - USP (São Paulo, SP, Br); Mestre e Doutor em Teoria Psicanalítica pela Universidade Federal do Rio de Janeiro - UFRJ (Rio de Janeiro,RJ, Br), Psicólogo pela Universidade Federal de Santa Maria (Santa Maria, RS, Br); Professor Associado da Faculdade de Ciências Humanas e Professor do Programa de Pós-Graduação em Educação - mestrado e doutorado da Universidade Federal de Mato Grosso do Sul.- UFMS (Campo Grande, RS, Br).

Universidade Federal de Mato Grosso do Sul

Departamento de Ciências Humanas

Cidade Universitária, s/n, Sala 3, FACH

Cidade Universitária

Caixa Postal 549

79070-900 Campo Grande, MS, Br Brasil

URL da Homepage: http://www.dch.ufms.br

tiagoravanello@yahoo.com.br

https://orcid.org/0000-0002-1723-9793

\section{Marcio Luis Costa}

Mestrado e Doutorado em Filosofía pela Universidad Nacional Autónoma de Mexico, UNAM (México. ME); Graduação em Filosofia na Universidade Católica Dom Bosco UCDB (Campo Grande, MS, Br); Professor do Programa de Mestrado e Doutorado em

74 Psicologia da Universidade Católica Dom Bosco - UCDB.

Av. Tamandaré, 6000 - Jardim Seminário - Prédio da Biblioteca

79117-900 Campo Grande, MS, Br

marcius1962@gmail.com

https://orcid.org/0000-0003-0412-4812

This is an open-access article, which permits unrestricted use, distribution, and reproduction in any medium for non-commercial purposes provided the original authors and sources are credited. 